\title{
Determination of $\mathrm{Al}$ in Sample of $\mathrm{Zn}$ Hot Dip Galvanizing Bath by $\mathrm{X}$-ray Fluorescence Spectrometry
}

Yoshiro Matsumoto

\section{Synopsis :}

In the production of $\mathrm{Zn}$ hot dip galvanized steel sheets, the concentration of $\mathrm{Al}$ in the galvanizing bath must be maintained within a limited range to ensure optimum performance. For this purpose, an accurate determination of $\mathrm{Al}$ by $\mathrm{X}$-ray fluorescence spectrometry was studied.

The results were as follows :

(1) The AlK $\alpha$ line intensity increased with the lapse of time after sample preparation because of the enrichment of $\mathrm{Al}$ in the near surface of the samples.

(2) An accurate analysis was performed by peparing a sample with an $\mathrm{SiC}$ abrasive paper of coarse grit size 40 and starting the $\mathrm{X}$-ray intensity measurement at a short time elapsed of 3 min after sample preparation.

Key words : Al concentration; $\mathrm{Zn}$ hot dip galvanizing; $\mathrm{X}$-ray fluorescence analysis ; sample preparation.

\section{1. 緒言}

溶融亜鉛めっき鋼板の製造では, めっき被膜の密着性 を向上させるために，亜鉛めっき浴中の $\mathrm{Al}$ の濃度を一 定の水準に維持することが必要となる1). めっき浴中の $\mathrm{Al}$ の濃度の分析には, 分析時間が短い点から, 蛍光 $\mathrm{X}$ 線分析法が広く用いられる22. しかし, 蛍光 X 線分析 法では, 試料研磨後の時間の経過とともに酸化による試 料表面での $\mathrm{Al}$ 成分の濃化により $\mathrm{AlK} \alpha$ 線の測定強度が 上昇するため, 分析の精度・正確さが劣化する.この分 析についての研究は比較的少なかった. 今回, (i) 試料 の研磨粗さ（ii）試料研磨後蛍光 $\mathrm{X}$ 線強度測定開始ま での経過時間が $\mathrm{AlK} \alpha$ 線強度および分析の精度・正確さ におよぼす影響について検討したので, その結果を述べ る.

\section{2. 実 験 方 法}

実験には走査型の蛍光 X 線分析装置 (理学電機工業, IKF-4 型）を用いた. 分析線には $\mathrm{AlK} \alpha$ および $\mathrm{ZnK} \alpha$ 線を選び $\mathrm{AlK} \alpha$ 線の強度は $\mathrm{Cr}$ 管球 $40 \mathrm{kV}-60 \mathrm{~mA}$, 分
光結晶 $\operatorname{PET}(002)^{3)}$ (Pentaerythritul, $\left.\mathrm{C}\left(\mathrm{CH}_{2} \mathrm{OH}\right)_{4}\right)$, $\mathrm{ZnK} \alpha$ 線の強度は $\mathrm{Cr}$ 管球 $25 \mathrm{kV}-2 \mathrm{~mA}$, 分光結晶 $\mathrm{LiF}$ (200) (Lithium Fluoride)，のそれぞれの条件で測定し た.

また, 試料表面の $\mathrm{Al}$ の濃化状況をグロー放電発光分光

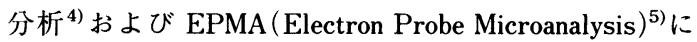
より調べた.グロー放電発光分光分析は電極径 $\phi 6 \mathrm{~mm}$, 放電電圧 $1000 \mathrm{~V}$ (定電圧モード), $\mathrm{Ar}$ 圧力 $530 \mathrm{~Pa}$, 分 析線 AlI $396.15 \mathrm{~nm}, \mathrm{ZnI} 334.50 \mathrm{~nm}$ の条件で行った。 EPMA による分析は加速電圧 $15 \mathrm{kV}$, 試料電流 $40 \mathrm{nA}$ の条件により, $\operatorname{ADP}(110)$ (Ammonium Dihydrogen Phosphate, $\left.\mathrm{NH}_{4} \mathrm{H}_{2} \mathrm{PO}_{4}\right)$ 分光結晶を用い $\mathrm{AlK} \alpha$ 線強度を, RAP (Rubidium Acid Phtalate, $\mathrm{RbHC}_{8} \mathrm{H}_{4} \mathrm{O}_{4}$ ) ) 分光結晶 を用い $\mathrm{OK} \alpha$ 線強度をそれぞれ測定した。

基準試料は実験室で作製し, 酸溶解後 ICP(Inductively Coupled Plasma Spectrometry) により $\mathrm{Al} の$ 濃 度を求めた. 分析試料の表面の研磨にはグリッド・サイ ズ (以下略) 40, 320 および 600 番の $\mathrm{SiC}$ 研磨紙 (以下

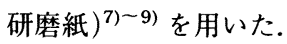




\section{3. 実験結果および考察}

( 1 )蛍光 X 線強度の時間的変化

試料研磨後, $\mathrm{AlK} \alpha$ 線および $\mathrm{ZnK} \alpha$ 線の強度が試料研 磨後の時間経過とともにどのように変化するかを調べ た. 試料研磨後, 蛍光 X 線分析装置の試料室に分析試 料を装入し, 分析試料室内を $1.3 \mathrm{~Pa}$ の真空状態にし, 試料を $30 \mathrm{rpm}$ で回転させ, レートメーターの時定数を $20 \mathrm{~s}$ として蛍光 X 線強度の測定を連続的に行った．分 析装置への試料装着㧍よび排気操作が必要なため試料研 磨終了から X 線強度測定開始までを $3 \mathrm{~min}$ としこの時 間を $\mathrm{X}$ 線強度開始点，また，それぞれの研磨紙粗さの 場合に測定開始時の強度を基準強度とし規格化して整理 した結果を Fig. 1 に示す。なお，予備実験により，大 気状態（試料室を大気圧にし，AlK $\alpha$ 線強度測定時のみ 間欠的に $1.3 \mathrm{~Pa}$ の真空状態にした場合）と試料室を常 時, $1.3 \mathrm{~Pa}$ の真空状態にした場合とで $\mathrm{AlK} \alpha$ 線強度の 変動には大きな差がないことを確認した。 $60 \mathrm{~min}$ 経過 後の $\mathrm{AlK} \alpha$ 線強度は 40,320 ，および 600 番の研磨紙に ついて, 研磨 $3 \mathrm{~min}$ 後の測定強度と比較するとそれぞれ $1.1,1.2$ および 1.3 倍程度となり, 粗い研磨紙の方が $\mathrm{AlK} \alpha$ 線強度の変動が少ない結果となった。この $\mathrm{AlK} \alpha$ 線強度が時間経過とともに強くなる現象は Fig. 2 のよ うに $120 \mathrm{~h}$ 放置した実験でも観察された。なお，この実 験では，大気中で試料を放置し， $\mathrm{AlK} \alpha$ 線強度の測定を $1.3 \mathrm{~Pa}$ の真空状態にし $100 \mathrm{~s}$ 行った.

ここで, $\mathrm{Zn}$ 中 $\mathrm{Al}$ の分析における $\mathrm{AlK} \alpha$ 線強度が試 料研磨後の時間経過とともに変化する程度を $\mathrm{Zn}$ 試料の $\mathrm{ZnK} \alpha$ 線強度および鋼試料の $\mathrm{AlK} \alpha$ 線強度と比較した。

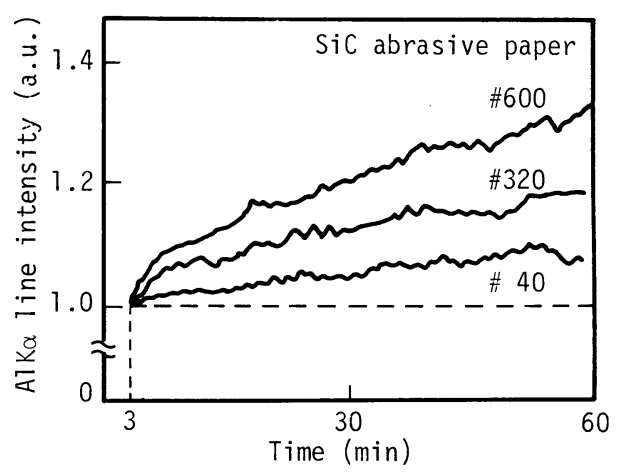

Fig. 1. Variation in the $\mathrm{AlK} \alpha$ line intensity as a function of the time elapsed after sample preparation with $\mathrm{SiC}$ abrasive papers of 40,320 and 600 grit size. The $\mathrm{Al}$ content in the $\mathrm{Zn}$ sample used for the experiment was $0.13 \%$.

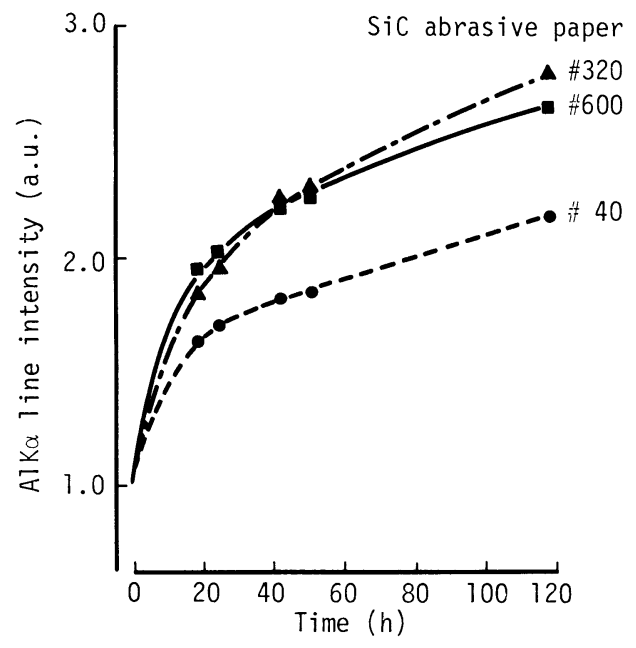

Fig. 2. Variation in the AlK $\alpha$ line intensity as a function of the time elapsed after sample preparation. The observation period was $120 \mathrm{~h}$ (See Fig. 1).

$\mathrm{Zn}$ 試料の $\mathrm{ZnK} \alpha$ 線強度を Fig. 3 に, $\mathrm{Fe}-\mathrm{Al}$ 二元系試 料として日本鉄鋼標準試料 JSS FXS353 試料 $(\mathrm{Al}=$ $0.18 \%)^{10)}$ の $\mathrm{AlK} \alpha$ 線強度を Fig. 4 に示す.いずれも $\mathrm{Zn}$ 試料の $\mathrm{AlK} \alpha$ 線強度に比較し, 時間的な変動が少な いことがわかる.

( 2 )試料表面の $\mathrm{Al}$ の濃化

研磨後の時間経過とともに $\mathrm{AlK} \alpha$ 線強度が高くなる原 因として試料表面の $\mathrm{Al}$ の濃化が考えられるのでグロー 放電発光分光分析法および EPMA により $\mathrm{Al}$ の濃化の 現象について調べた。試料研磨（320 番研磨紙）後, 16 $\mathrm{h}$ 経過 $(\mathrm{Al}$ の濃化現象を調べやすくするため長時間放 置した）後，グロー放電発光分光分析法により深さ力向 の $\mathrm{Al} と \mathrm{Zn}$ のプロフィール測定を行った。その結果を Fig. 5 に示す. 試料表面部の測定となる放電開始時で は $\mathrm{Al}$ の発光強度は強く, $\mathrm{Zn}$ の発光強度は弱いことか ら試料表面に $\mathrm{Al}$ が濃化していることがわかる。また， EPMA により研磨後 $150 \mathrm{~h}$ 経過（Al の濃化現象を調へ やすくするためグロー放電発光分光分析の場合より細か い600 番研磨紙を用い，さらに長時間放置した）後の 試料表面での $\mathrm{AlK} \alpha$ 線と $\mathrm{OK} \alpha$ 線の強度を試料研磨後放 置せずに分析を開始した場合と比較した。その結果を Fig. 6 に示す. 研磨後 $150 \mathrm{~h}$ 経過した試料では AlK $\alpha$ 線 および $\mathrm{OK} \alpha$ 線の強度が強いことから, 試料表面に酸化 反応による $\mathrm{Al}$ の濃化が生じたと考えられる11).

( 3 )研磨粗さの影響

$\mathrm{AlK} \alpha$ 線強度の時間的変動を入射および検出 $\mathrm{X}$ 線の 

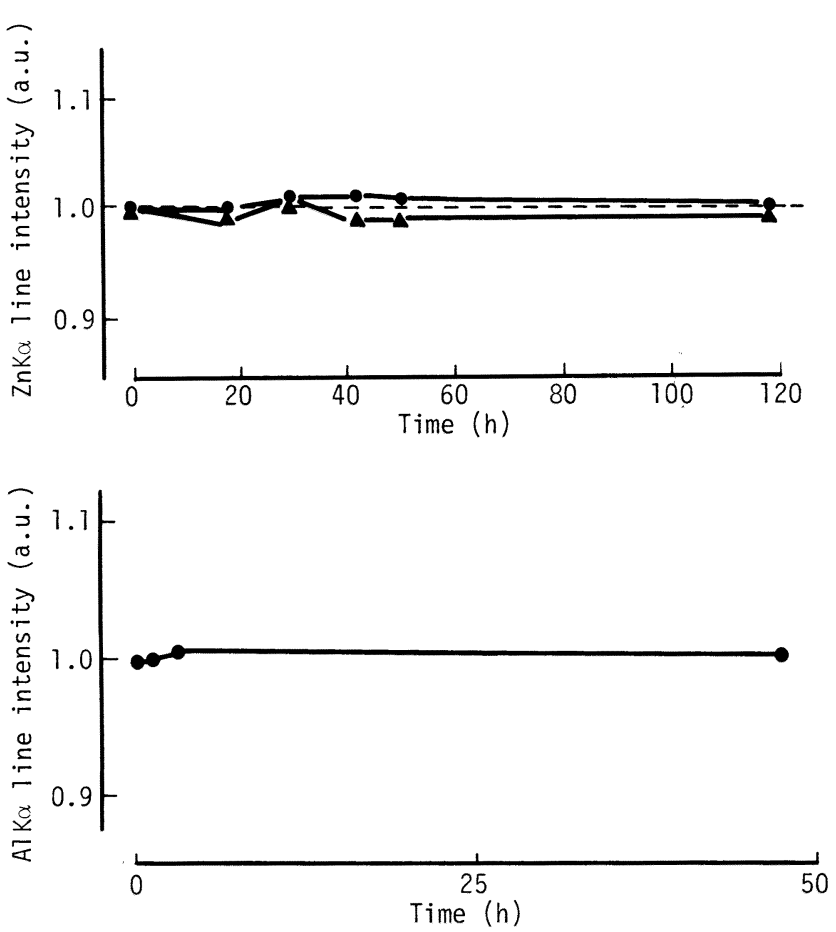

$\mathrm{SiC}$ abrasive papers : $\mathbf{O}$; $40, \boldsymbol{\Delta} ; \# 600$

Fig. 3. Variation in the $\mathrm{ZnK} \alpha$ line intensity as a function of the time elpsed after sample prepardtion.

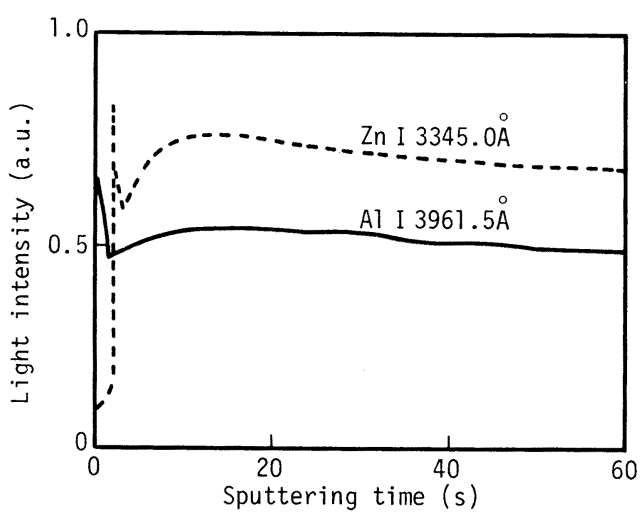

Sample preparation : $\mathrm{SiC}$ abrasive paper of 320 grit size Diameter of electrode : $\phi 6 \mathrm{~mm}$ Ar gas pressure : $530 \mathrm{~Pa}$ Discharge voltage : $1000 \mathrm{~V}$ const

Analytical lines : AlI $396.15 \mathrm{~nm}$, and $\mathrm{ZnI} 334.50 \mathrm{~nm}$

Fig. 5. Glow discharge spectrometric depth profile of a $\mathrm{Zn}$ sample containing $0.13 \% \mathrm{Al}$ measured at $16 \mathrm{~h}$ after sample preparation.

研磨方向に対する角度が直角の場合と平行の場合で比 較 ${ }^{712)}$ した結果を 40,320 および 600 番の研磨紙につ いて Fig. 7 に示す. 320, 600 番では直角と平行の場合 とで $\mathrm{AlK} \alpha$ 線強度の時間的変動にほとんど差がない.し .かし, 40 番では平行の場合には時間的経過とともに変
動するのに対して, 直角の場合には時間的な変動は少な い.ここで AlK $\alpha$ 線について無限大厚さの試料で検出さ れる強度の $99 \%$ が得られる厚さ (有効厚さ) ${ }^{13)}$ を入射 $\mathrm{X}$ 線 $\mathrm{CrK} \alpha$ 線，入射角 $60^{\circ}$, 取出角 $35^{\circ}, \mathrm{Zn}$ の $\mathrm{CrK} \alpha$ 線および $\mathrm{AlK} \alpha$ 線に対する質量吸収係数をそれぞれ 180 $\mathrm{cm}^{2} / \mathrm{g}^{14)}$ および $4200 \mathrm{~cm}^{2} / \mathrm{g}^{14)}$ として計算すると 0.86 $\mu \mathrm{m}$ となる。 それぞれの研磨紙での研磨の深さは 40 番 研磨紙の場合では検出される $\mathrm{AlK} \alpha$ 線は試料表面の研磨 筋の山の極先端部だけからであることがわかる.この場 合，研磨筋に平行に X 線の照射・検出を行うと $\mathrm{Al}$ の濃 化の現象が $\mathrm{AlK} \alpha$ 線強度の上昇として現れる.これに対 して, 直角方向の $\mathrm{X}$ 線照射・検出では試料方向の谷の方 に生じた $\mathrm{Al}$ の濃化は $\mathrm{X}$ 線のシールド効果 ${ }^{5)}$ のため, $\mathrm{AlK} \alpha$ 線強度の上昇として検出され難く, その結果とし て時間的な $\mathrm{AlK} \alpha$ 線強度の上昇は少ないと考えられる.

\section{(4)分析の正確さ}

$\mathrm{AlK} \alpha$ 線強度と $\mathrm{Al}$ 量の関係を Fig. 8 に示す. 研磨を 行って $60 \mathrm{~min}$ 経過では $3 \mathrm{~min}$ 経過後測定を開始した場 合に比較し，それぞれの試料の強度は増加しており検量 線は高強度側になっている. $60 \mathrm{~min}$ 経過の $0.15 \% \mathrm{Al}$

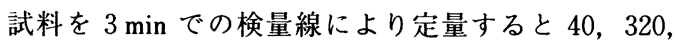
600 番研磨紙において, それぞれ 0.010，0.020，0.046\% 高く定量されることになる。このため, 研磨終了から測 

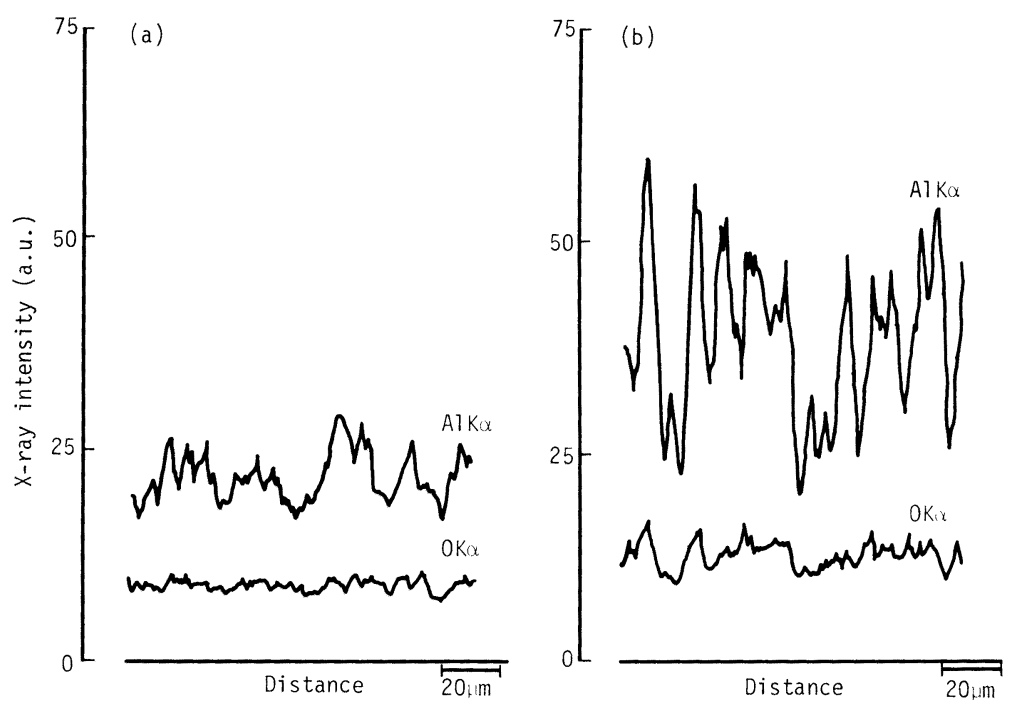

Sample preparation : $\mathrm{SiC}$ abrasive paper of 600 grit size Electron acceleration voltage : $15 \mathrm{kV}$ Specimen current : $40 \mathrm{nA}$ Analyzing crystals : $\mathrm{ADP}$ for $\mathrm{AlK}_{a}$ line and $\mathrm{RAP}$ for $\mathrm{OK}_{a}$ line

Fig. 6. Electron probe microanalysis of the polished surface of a $\mathrm{Zn}$ sample containing $0.13 \% \mathrm{Al}$. The analysis began at (a) $3 \mathrm{~min}$ and (b) $16 \mathrm{~h}$ after sample prepara tion.

(a) Cross section of sample surface

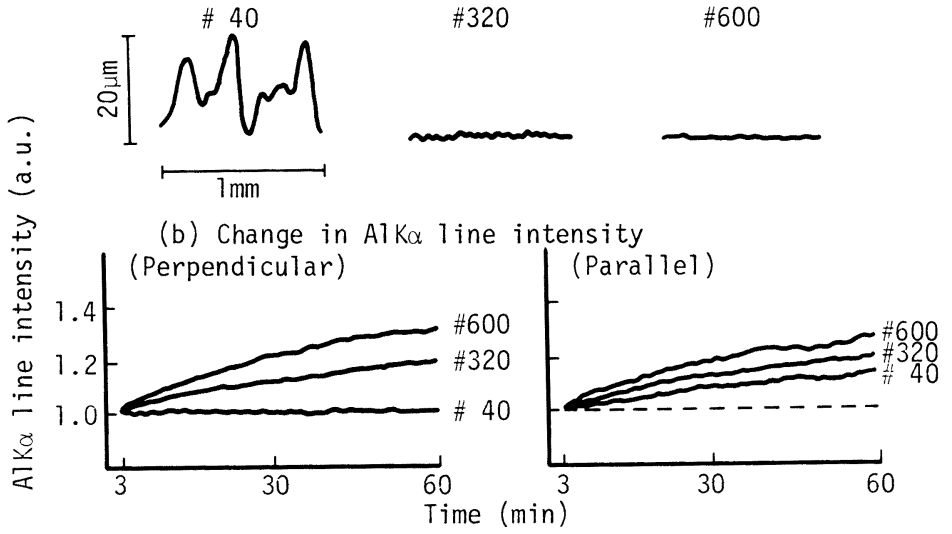

Perpendicular: The polishing striations perpendicular to $\mathrm{X}$-ray beam

Parallel : The polishing striations parallel to $\mathrm{X}$-ray beam

Fig. 7. Effect of abrasive paper grit size and the direction of $\mathrm{X}$-ray beam to sample surface striations on $\mathrm{AlK} \alpha$ line intensitytime curves.

定開始までの時間を規定せずにX 線強度測定を行うと 分析の精度・正確さが劣ることがわかる.

ここで, 分析の正確さ $\sigma_{d}\left(=\sqrt{\sum d^{2} /(n-1)}, d=\right.$ 蛍光 $\mathrm{X}$ 線分析値-化学分析値, $n=$ 試料数) を Table 1 のよ うに 40，320，600 番の研磨紙および $3 \mathrm{~min}, 60 \mathrm{~min} の$ 経過時間について求めた. 研磨後 $3 \mathrm{~min}$ での分析では 40，320，600 番の研磨紙について, 正確さはそれぞれ $0.002 \%, 0.003 \%, 0.004 \%$ と研磨粗さの粗い方が分析 の正確さは良好であった。 また, 研磨後 $60 \mathrm{~min}$ 経過に おいて X 線測定を行った場合に 60 min 経過の検量線で
Table 1. Analytical accuracy $\left(\sigma_{d}, \mathrm{wt} \%\right)$,

\begin{tabular}{c|ccc}
\hline \multirow{2}{*}{$\begin{array}{c}\text { Time } \\
(\mathbf{m i n})\end{array}$} & \multicolumn{3}{|c}{ SiC abrasive paper } \\
\cline { 2 - 4 } & $\# 40$ & $\# 320$ & $\# 600$ \\
\hline 3 & 0.002 & 0.003 & 0.004 \\
60 & 0.004 & 0.004 & 0.007 \\
\hline
\end{tabular}

Note; Time means the $\mathrm{X}$-ray measurement starting time after sample preparation.

定量すると 40，320，600 番研磨紙について，それぞれ $0.004 \%, 0.004 \%, 0.007 \%$ となった。研磨後 $3 \mathrm{~min}$ の 正確さよりやや少るが，それぞれの試料について経過時 


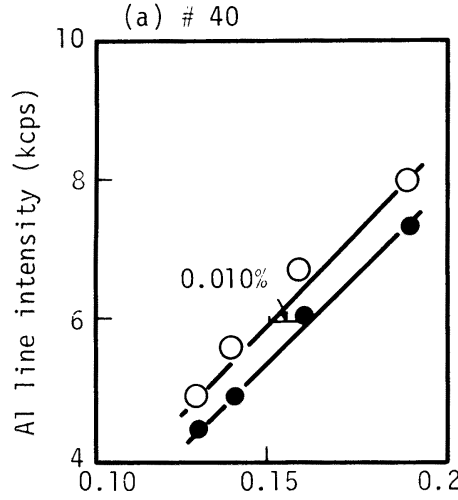

(b) $\# 320$

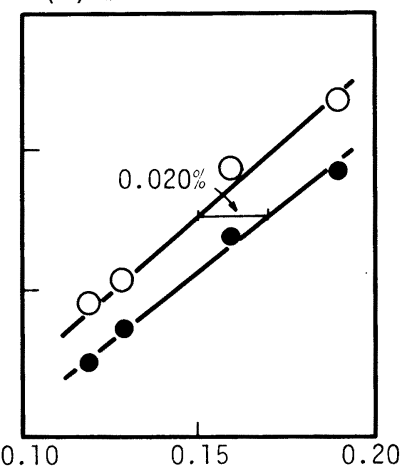

Al (wt \%) (c) $\# 600$

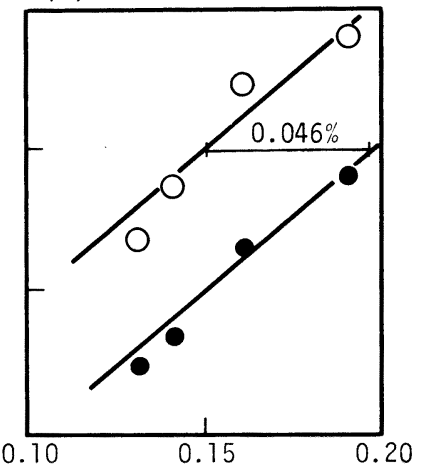

$\mathrm{X}$-ray measurement starting time after sample preparation : $; 3 \mathrm{~min}, \bigcirc ; 60 \mathrm{~min}$

Fig. 8. Analytical curves as a function of the time elapsed after surface preparation and SiC abrasive paper grit size.

閏に対する $\mathrm{Al}$ の濃化の状況がほぼ等しいと考えられる ため比較的良好な正確さが得られたと考えられる。

金属試料中の $\mathrm{Si}, \mathrm{Al}, \mathrm{Mg}$ 等の軽元素の䖺光 $\mathrm{X}$ 線分 析においては $2,3 \mu \mathrm{m}$ より深い研磨痕では分析の正確 さを著しく少化させるため細かい試料研磨が良いとされ ている31713)15). しかし, 本研究で対象にした Zn 中の $\mathrm{Al}$ の蛍光 X 線分析では時間の経過とともに試料表面に 酸化による $\mathrm{Al}$ の濃化が生じ, バルクと蛍光 X 線分析 で対象となる試料表面部とで $\mathrm{Al}$ 濃度が異なるという現 象が生じる。この時, 細かい研磨紙による試料研磨では 試料表面の $\mathrm{Al}$ の濃化による $\mathrm{AlK} \alpha$ 線測定強度の上昇速 度が速いため, 320, 600 番の細かい研磨より 40 番の粗 い研磨紙の方が AlK $\alpha$ 線測定強度の時間的な変動を小さ くでき良い分析の正確さが得られる結果となった。

\section{4. 結言}

$\mathrm{Zn}$ 中の $\mathrm{Al}$ の蛍光 $\mathrm{X}$ 線分析においては研磨後の時間 経過とともに試料表面の $\mathrm{Al}$ の濃化が進み $\mathrm{AlK} \alpha$ 線強度 が上昇する，上昇の程度は試料研磨粗さにより異なり， 研磨終了後 $60 \mathrm{~min}$ では 40,320, 600 番の $\mathrm{SiC}$ 研磨紙 の場合に，それぞれ研磨後 $3 \mathrm{~min}$ の $1.1,1.2$ および 1.3 倍であった。このため分析の精度・正確さを維持す るには試料の研磨終了から X 線強度測定開始までの時 間を $3 \mathrm{~min}$ 程度の一尘時間にする必要がある。研磨後 3 $\min$ で測定を行った場合の分析の正確さ $\left(\sigma_{d}\right)$ を 40,320 , 600 番の研磨紙について比較すると, それぞれ 0.002 , $0.003,0.004 \%$ であり AlK $\alpha$ 線強度の上昇速度が最も
遅い 40 番研磨紙で最も良い結果が得られた.

\section{文献}

1) 大部 操, 麻川健一, 田野和広: 鉄と鍴, 60 (1974), p. 705

2 ）加島尚武，佐伯正夫: 日本鉄鋼業における分析技術（日本 鉄銅協会共同研究会鉄鋼分析部会編）（1982）, p. 141

3 ) H. K. HeRglotZ and L. S. BirKS: X-Ray Spectrometry (1978), p. 10, p. 279, p. 282, p. 316 [Marcel Dekker, New York and Basel]

4 ) 広川吉之助, 岡垣 博: 原子スペクトル分析 (日本分析化 学会編) (1979), p. 190 [丸善]

5 ) K. F. J. HeinRICH: Electron Probe Microanalysis (1981) [Van Nostrand, New York]

6 ) 田中英樹: 日本化学会誌 (1977)2, p. 232

7 ) $R$. Tertian and $F$. Claisse: Principles of Quantitative X-Rey Fluorescence Analysis (1982), p. 317 [Heyden London]

8 ) JIS R6252 (1976)

9 ) $R$. Jenkins, $R$. W. Gould and $D$. Gedocke: Quantitative X-Ray Spectrometry (1981), p. 371 [Marcel Dekker, New York and Basel]

10）鉄鋼の工業けい光 $\mathrm{X}$ 線分析法 (日本鉄鋼協会鉄鋼分析部 会けい光 X 線分析分科会編）(1973),p. 177

11）前田重義, 浅井恒敏, 鈴木堅市, 樋口正順: 鉄と鋼, 64 (1978), A 139

12) E. P. BERTIN: Introduction to X-Ray Spectrometric Analysis (1978), p. 403 [Plenum, New York]

13) E. P. Bertin: Principles and Practice of $\mathrm{X}$-Ray Spectrometric Analysis (1970), p. 457 [Plenum New York ]

14) L. S. Birks: Electron Probe Microanalysis (1963), p. 201 [Interscience Publishers, New York]

15) H. A. Liebhafsky, $H$. G. Pfeiffer, $E$. $H$. Winslow and $P$. D. Zemany: X-Ray, Electrons, and Analytical Chemistry (1972), p. 442 [Wiley-Interscience, New York] 